\title{
Inequalities of access to bariatric surgery in Australia
}

\author{
Bariatric surgery for obesity complicated by severe comorbid conditions should \\ be accessible to all Australians
}

\section{Michael Edye MBBS, FRACS, FACS Professor of Surgery' \\ Michael L Talbot MBChB, FRACS Senior Lecturer ${ }^{2}$ \\ 1 Blacktown/Mt Druitt Clinical School, University of Western Sydney, Sydney, NSW. \\ 2 Department of Surgery, St George Hospital, Sydney, NSW. \\ M.Edye@uws.edu.au}

doi: 10.5694/mjal4.01169 randomised controlled trials and authoritative systematic reviews, comes predominantly from work carried out in the private sector.

Bariatric surgery has long been established as the only treatment for the morbidly obese that durably addresses the mechanical effects of obesity, such as sleep apnoea and joint disease, while producing profound metabolic changes including resolution of type 2 diabetes mellitus (T2DM), hypertension and dyslipidaemia. Yet, unlike for other chronic illnesses such as asthma, diabetes and joint disease, Australia still has no framework within which obesity treatment of any kind, including surgery, can be offered to all. While surgery is available for public patients in some Australian states, the services are poorly funded and oversubscribed or, as is the case in New South Wales and Queensland, almost completely absent.

There is solid evidence that the expense of surgery will be offset by reduced costs of managing comorbid conditions, yielding improved quality and length of life, as well as by reduced costs of medication and food..$^{2-4}$ For those with T2DM, the savings from eliminating the substantial annual direct and indirect costs of medical treatment can pay for surgery in a year or so.

While the scientific and business cases for bariatric surgery might be strong, in the absence of a coherent funding model, savings accrued in the care of the associated chronic illnesses (largely a federal expense) are not directly available to fund surgical care (a state expense). There is no doubt that persisting attitudes among the medical profession, health administrators and politicians have led to an inadequate will for and understanding of how obesity surgery can be successfully translated into a public hospital setting on a wide enough scale. The prospect of uncontrolled bariatric surgery in the public sector raises the spectre of swelling waiting lists and budgetary overruns from hospital readmissions for revisional surgery and complication management. ${ }^{5,6}$
While the female preponderance of patients in reported series ${ }^{1-4,7,8}$ may fuel the prejudice that bariatric surgery is merely cosmetic, studies examining mortality rates and comorbid conditions ${ }^{9}$ show that the population of patients ideally targeted in a public bariatric clinic will manifest clear health improvements after surgery. In obese patients with severe comorbid conditions, health is as impaired as in those with malignancy or cardiac ischaemia. ${ }^{10}$ When faced with an overwhelming demand for a finite resource, a rational approach to cost concerns is to focus on surgery to treat sickness rather than fatness. Body mass index alone is not as good a selection criterion as the presence of serious obesity-associated conditions that are inadequately responsive to standard medical therapies. In this setting, bariatric surgery is best practice.

Treatment-adherent public patients need to be referred for bariatric surgery by a clinician treating their refractory comorbid conditions (eg, tablet-controlled diabetes now requiring insulin). Given the resources being used, the final recommendation for surgery should be made in a multidisciplinary team-like structure. These measures will help assure cost-effective surgery and patient adherence. Equally, performing surgery on patients who are non-adherent with their medical therapies risks their non-adherence to nutritional and supplement advice afterwards.

Innovative public-private collaborations between bariatric surgeons and local health district-based bariatric centres can furnish the case and personnel volume (in excess of 50-100 cases annually per team) needed for a meaningful impact on patient numbers and mandatory to maintain skill levels and clinical coverage for well performed, safe surgery.

The establishment of a definitive dataset for both public and private sectors is now feasible with the development of the Monash University-based Bariatric Surgery Registry. ${ }^{7}$ Lifelong collection of data vital to the understanding of metabolic disease could be facilitated by the creative use of the national e-health record, with input perhaps from the new generation of wearable computers to track physical activity and metabolic indices. The challenge will be to achieve buy-in by bean counters and bariatric surgeons with the acknowledgement that life-threatening complications of severe obesity merit best-practice treatment.

Acknowledgements: We thank Clare Bouffler for her help compiling the references.

Competing interests: No relevant disclosures.

Provenance: Commissioned; externally peer reviewed. 
1 Lukas N, Franklin J, Lee CMY, et al. The efficacy of bariatric surgery performed in the public sector for obese patients with comorbid conditions. Med J Aust 2014; 201: 218-222.

2 Talbot ML, Jorgensen JO, Loi KW. Difficulties in provision of bariatric surgical services to the morbidly obese. Med J Aust 2005; 182: 344-347.

3 Dixon JB, O'Brien PE, Playfair J, et al. Adjustable gastric banding and conventional therapy for type 2 diabetes: a randomized controlled trial. JAMA 2008; 299: 316-323.

4 Brethauer SA, Aminian A, Romero-Talamás H, et al. Can diabetes be surgically cured? Long-term metabolic effects of bariatric surgery in obese patients with type 2 diabetes mellitus. Ann Surg 2013; 258: 628-636.

5 Zingmond DS, McGory ML, Ko CY. Hospitalization before and after gastric bypass surgery. JAMA 2005; 294: 1918-1924.
6 Hamdan K, Somers S, Chand M. Management of late postoperative complications of bariatric surgery. Br J Surg 2011; 98: 1345-1355.

7 Second report of the pilot bariatric surgery registry. Melbourne: Monash University, 2014. http://www.med.monash.edu.au/assets/docs/sphpm/ second-report.pdf (accessed Sep 2014).

8 Schaver PR, Bhatt DL, Kirwan JP, et al. Bariatric surgery versus intensive medical therapy for diabetes - 3-year outcomes. NEngl J Med 2014; 370: 2002-2013.

9 Siöström L. Review of the key results from the Swedish Obese Subjects (SOS) trial - a prospective controlled intervention study of bariatric surgery. J Intern Med 2013; 273: 219-234.

10 Prospective Studies Collaboration; Whitlock G, Lewington S, Sherliker P, et al. Body-mass index and cause-specific mortality in 900000 adults: collaborative analyses of 57 prospective studies. Lancet 2009; 373: 1083-1096. 